\title{
Tratamento anticalcificante de bioprótese: resultado clínico inicial
}

\author{
Mário O. VANDRECIC*, Bayard GONTIJO FILHO*, Sérgio Almeida de OLIVEIRA**, João Alfredo de \\ PAULA E SILVA*, Fernando Antônio FANTINI*, Juscelino Teixeira BARBOSA*, Sandra de Oliveira

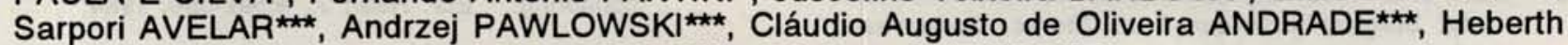

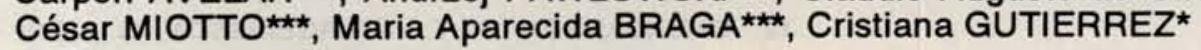

VANDRECIC, M. O.; GONTIJO FILHO, B.; OLIVEIRA, S. A.; PAULA E SILVA, J. A.; FANTINI, F. A.; BARBOSA, J. T.; AVELAR, S. O. S.; PAWLOWSKI, A.; ANDRADE, C. A. O.; MIOTTO, H. C.; BRAGA, M. A.; GUTIERREZ, C. - Tratamento anticalcificante de bioprótese: resultado clínico inicial; Rev. Bras. Cir. Cardiovasc., 7 (2):112-120, 1992.

RESUMO: O resultado clínico das trocas valvares com o uso de bioprótese é satisfatório do ponto de vista hemodinâmico e da baixa incidência de tromboembolismo, proporcionando uma qualidade de vida adequada. A durabilidade, principalmente em crianças e jovens, tem sido a principal desvantagem. Embora vários tratamentos tenham sido divulgados como o remédio eficaz contra a calcificação, os resultados das biopróteses de primeira, segunda e terceira geração são os mesmos. Este trabalho analisa os resultados clínicos iniciais das trocas valvares utilizando a bioprótese porcina Biocór tratada, usando-se uma nova metodologia múltipla de modo a se obter uma ligaçāo covalente duradoura do agente anticalcificante ao tecido. Os resultados convincentes obtidos na experimentaçāo animal, a qualidade da análise toxicológica e a necessidade de um substituto valvular biológico determinaram este estudo clínico em 55 pacientes, nos quais foram implantadas 66 biopróteses. De fevereiro de 1991 a março de 1992, receberam esta nova bioprótese 28 pacientes do sexo masculino e 27 do sexo feminino. A idade variou de 11 a 68 anos. A idade média foi de 26,6 anos. As médias das idades foram de $25,5 \pm 3,6$ para os pacientes do sexo masculino e $27,9 \pm 4,8$ para os do sexo feminino; $72,7 \% \pm 11,8$ dos pacientes pertencem ao grupo etário de até 30 anos. A etiologia foi essencialmente reumática em $70,9 \% \pm 12,0$. O ritmo sinusal predominou em $70,9 \%$ e a classe funcional préoperatória foi de $40,0 \% \pm 12,9$ e de $52,7 \% \pm 13,2$ para a classe III e IV, respectivamente, da NYHA. Esses 55 pacientes (pts) foram submetidos a troca aórtica $(16 \mathrm{pts}=29,1 \% \pm 12,0)$; mitral $(28 \mathrm{pts}=50,1 \% \pm 13,21)$ e dupla troca ( $11 \mathrm{pts}=20,0 \% \pm 10,6)$. A técnica cirúrgica foi a convencional, usando-se oxigenador nacional de bolhas, cardioplegia cristalóide e pontos em U sub-anulares. Nảo houve complicaçōes relacionadas à nova bioprótese per si. A mortalidade hospitalar foi 3,6\% $\pm 4,9$ ( 2 em $55 \mathrm{pts}$ ). A maioria dos pacientes encontrase em classe funcional l e II. O seguimento desses pacientes é feito trimestralmente, através de exame clínico, ecodopplercardiografia e análises sangūíneas. Durante esse período de 13 meses de seguimento, nāo foi detectada nenhuma alteração decorrente do uso desta nova bioprótese. Embora o tempo de seguimento tenha sido curto, pode-se observar que a natureza do tratamento químico realizado na bioprótese foi bem tolerada. À luz dos resultados experimentais satisfatórios na obtençāo de um tratamento que atenue a calcificação, prolongando a durabilidade, os autores justificam a necessidade de estudos controlados na busca do substituto valvular ideal.

DESCRITORES: próteses valvulares cardíacas, biológicas, cirurgia; valvas cardíacas, cirurgia.

Trabalho realizado no Biocór Hospital de Doenças Cardiovasculares, Belo Horizonte, MG; no Hospital da Beneficência Portuguesa, São Paulo, SP e na Santa Casa de Misericórdia de Belo Horizonte, MG, Brasil.

Apresentado ao $19^{\circ}$ Congresso Nacional de Cirurgia Cardiaca. São Paulo, SP. 7 a 9 de maio de 1992.

* Do Biocór Hospital de Doenças Cardiovasculares e da Santa Casa de Misericórdia de Belo Horizonte.

* Do Hospital da Beneficência Portuguesa de Sáo Paulo.

- Do Biocór Hospital de Doenças Cardiovasculares.

Endereço para separatas: Mário Vrandecic. Caixa Postal 106. 30161 Belo Horizonte, MG, Brasil. 
VANDRECIC, M. O.; GONTIJO FILHO, B.; OLIVEIRA, S. A.; PAULA E SILVA, J. A.; FANTINI, F. A.; BARBOSA, J. T.; AVELAR, S. O. S.; PAWLOWSKI, A.; ANDRADE, C. A.; MIOTTO, H. C.; BRAGA, M. A.; GUTIERREZ, C. - Tratamento anticalcificante de bioprótese: resultado clínico inicial; Rev. Bras. Cir. Cardiovasc., 7 (2):112-120, 1992.

\section{INTRODUÇĀO}

A doença reumática ainda é o principal fator etiológico determinante da disfunção valvar cardíaca. Embora o tratamento cirúrgico conservador através das plastias tenha alcançado um alto índice técnico e resultados satisfatórios, o grau avançado da seqüela valvar, encontrada durante a cirurgia, indica a necessidade das trocas valvares ${ }^{3,12}$.

Dos substitutos valvares cardíacos existentes no mercado, as próteses mecânicas têm uma durabilidade teórica superior; todavia, necessitam uso permanente de anticoagulantes, cuja dificuldade no manuseio, custo e complicaçōes constituem grande desvantagem '.

O uso do homoenxerto em posição aórtica, de resultados aparentemente satisfatórios, tem restriçōes de estoque legais e técnicas ${ }^{2}$.

As biopróteses, em uso desde 1967, têm características hemodinâmicas satisfatórias, não sendo necessário o uso de anticoagulantes, proporcionando melhor qualidade de vida. Todavia, a sua durabilidade, principalmente em crianças e jovens, não é a esperada?

Os processos degenerativos do tecido biológico e a calcificaçāo constituem as complicaçōes mais comuns que determinarão a sua limitada durabilidade. No nosso país, a idade média dos pacientes necessitando trocas valvares é de 34 anos e é preoisamente nessa faixa etária que as biopróteses têm a sua durabilidade reduzida. $O$ desenvolvimento de tratamento específico no tecido biológico, que prolongue a durabilidade desses substitutos valvares biológicos é, hoje, uma necessidade ${ }^{13}$.

A pesquisa do processo de calcificação das biopróteses, especificamente dos mecanismos da mesma, em vigência do tratamento pelo glutaraldeído, é desconhecido. O estágio inicial da calcificação parece estar associado aos fosfolípides da membrana celular. Nos estágios avançados envolve, principalmente, as fibras colágenas, determinando graves disfunçōes da bioprótese ${ }^{10}$.

A calcificaçāo está relacionada ao tratamento do tecido biológico com o glutaraldeído, já que o conteúdo de cálcio é proporcional à quantidade de aldeído incorporado ao mesmo ${ }^{5,11}$. As modificaçōes químicas responsáveis pela atração do cálcio a este tecido e a conseqüente mineralização do mesmo não são conhecidas.

Vários são os tratamentos anticalcificantes preconizados até o momento, tais como o uso de detergentes, o bifosfonato, a incorporação polimérica e outros ${ }^{8}$, cuja espectativa inicial foi grande; todavia, os resultados clínicos, ao longo do tempo, demonstraram, que esses agentes foram facilmente lavados pelo fluxo, de efeito temporário e sem nenhum impacto positivo na durabilidade.

A prevalência da doença reumática, seqüelas valvares freqüentes observadas em crianças e jovens no nosso meio, necessitando uma bioprótese durável, a existência de um tratamento alternativo no processamento do tecido biológico que prolongue essa durabilidade pelo seu efeito anticalcificante, demonstrado em animais de experimentação, assim como a comprovada tolerância in vitro desse tecido tratado pelo "processo P.S." determinaram este estudo clínico inicial.

\section{MATERIAL E MÉTODOS}

O material deste estudo está dividido em quatro ítens: experimentação animal, análise citotóxica, teste de fadiga e estudo clínico.

\section{Experimentaçāo Animal}

As biopróteses porcinas Biocór, tratadas pelo processo anticalcificante, serão aqui referidas com a sigla P.S. Após o tratamento, foram conservadas em solução de formadeído a $3 \%$ e embaladas de modo rotineiro.

Foram usadas biopróteses com o tratamento convencional (grupo controle) e o tratamento específico (grupo P.S.).

A eficácia do tratamento anticalcificante foi determinada por implante heterotópico do tecido valvar em ratos do sexo masculino de peso entre 180 a 200 gramas e, posteriormente, por implantes ortotópicos em carneiros de peso inferior a $100 \mathrm{~kg}$.

O experimento inicial, realizado em ratos, constituiu-se do implante de fragmentos valvares de $3 \mathrm{~mm}$ no subcutâneo, sendo que, no primeiro estudo, foram inseridos três fragmentos no grupo controle e três fragmentos no grupo $P$. S. No segundo estudo, apenas um fragmento de cada tipo. A duração do estudo variou de 3 a 15 semanas. Após a remoção do fragmento, este foi lavado, seco e submetido à ação da hidrólise ácida. O conteúdo do cálcio deste material hidrolisado foi determinado usando-se a titulação fluorométrica no analisador da Corning modelo 940, ou, se necessário, a espectroscopia de absorção atômica.

A segunda parte da avaliação foi feita pelo implante ortotópico em carneiros na posição mitral, em número de 6 animais para o grupo controle e de 6 para $\circ$ grupo P.S.

O experimento teve a duração de seis meses, todas as biopróteses implantadas foram retiradas, 
VANDRECIC, M. O.; GONTIJO FILHO, B.; OLIVEIRA, S. A.; PAULA E SILVA, J. A.; FANTINI, F. A.; BARBOSA, J. T.; AVELAR, S. O. S.; PAWLOWSKI, A.; ANDRADE, C. A.; MIOTTO, H. C.; BRAGA, M. A.; GUTIERREZ, C. - Tratamento anticalcificante de bioprótese: resultado clínico inicial; Rev. Bras. Cir. Cardiovasc., 7 (2):112-120, 1992.

analisadas visual, radiológica e fotograficamente. A análise histológica foi feita com microscopia de luz e eletrônica. $A$ análise bioquímica dos folhetos foi realizada retirando-se segmentos de cada um, com a designação de corpo e base. Esses tecidos secos, adequadamente identificados e de peso conhecido, foram submetidos a hidrólise e determinaçāo do conteúdo do cálcio, seguindo-se a metodologia acima descrita. O restante das biopróteses foi conservado em solução de formaldeído.

\section{Análise Citotóxica}

Foram realizados vários testes de citotoxicidade, usando-se fragmentos de biopróteses porcinas tratadas.

1) Teste de citotoxicidade para fibroblasto humano

a - Meio de cultura: RPMI-1640 $+1 \%$ de aminoácidos não essenciais $+15 \%$ de soro fetal bovino $+1 \%$ de antibiótico antimicótico.

b - Condiçōes de cultura: utilizamos "FLAKS" de $75 \mathrm{~cm}^{2}$ a $150 \mathrm{~cm}^{2}$ para o crescimento dos fibroblastos sendo o meio de cultura substituído de 3 em 3 dias.

c - "Harvest": os fibroblastos foram obtidos dos "FLAKS" com tratamento à base de TRYPIN EDTA (Gibco).

d - Cell line utilizada:

Fibroblastos 1521: pele humana normal

Fibroblastos 153: pulmão humano normal

2) Implante de material porcino valvar tratado no tecido subcutâneo de coelhos durante sete dias.

3) Teste de fragilidade de hemácias em contato com fragmentos de tecido de biopróteses porcinas tratadas.

\section{Teste de Fadiga}

As biopróteses tratadas pelo P. S. foram testadas no duplicador de pulso por períodos superiores a 50 milhōes de ciclos, usando-se os requisitos sugeridos por GABBAY'.

\section{Estudo Clínico}

De feveiro de 1991 a março 1992, foram implantadas 66 biopróteses tratadas pelo processo P.S., em 55 pacientes: 25 no Biocór Hospital, Belo Horizonte; 16 no Hospital da Beneficência Portuguesa, Sảo Paulo e 14 na Santa Casa de Misericórdia, Belo Horizonte; 28 pacientes eram do sexo masculino e 27 do feminino; a idade variou de 11 a 68 anos, sendo 40 pacientes com idade igual ou inferior a 30 anos $(72,7 \% \pm 11,8)$; a idade média foi de 26,6 anos.
O seguimento foi de 489 meses, isto é, de 9 meses/paciente. A classe funcional pré-operatória mostra 4 pacientes em grupo II, 22 em grupo III e 29 pacientes em grupo IV. A etiologia foi reumática em 39 pacientes $(70,9 \% \pm 12,0)$, endocardite em 8 pacientes $(14,5 \% \pm 9,3)$ e degenerativa em 8 pacientes $(14,5 \% \pm 9,0)$. O ritmo cardíaco pré-operatório foi sinusal em $70,9 \% \pm 12,0$ e fibrilação atrial em $29,1 \% \pm 12,0$.

O procedimento cirúrgico realizado foi a troca aórtica em 16 pacientes, troca mitral em 28 e dupla troca em 11 pacientes.

A técnica usada foi a convencional, utilizandose oxigenadores de bolha nacionais, cardioplegia cristalóide tipo St. Thomas e pontos em U separados.

Seguimento pós-operatório: todos os pacientes estão sendo examinados trimestralmente através de exames clínico, ecodopplercardiográfico e hematológico.

A avaliação ecodopplercardiográfica das biopróteses tratadas segue este protocolo: no grupo aórtico, a avaliaçảo estrutural da bioprótese foi feita a partir do módulo $\mathrm{M}$ e bidimensional, estudandose textura, movimentação, abertura e fechamento.

A avaliação pelo doppler pulsado e pelo mapeamento do fluxo a cores foi realizada para a pesquisa de possivel insuficiência valvar. $A$ área valvar foi calculada a partir da equaçāo de continuidade:

$$
A_{2}=\frac{A_{1} \times V_{1}}{V_{2}} \quad A_{1}=\frac{\| \times(D)^{2}}{2}
$$

Do doppler contínuo foram calculados o pico de gradiente e o gradiente médio.

O grupo mitral foi estudado pelo módulo $\mathrm{M}$ e bidimensional observando-se os mesmos parâmetros descritos para o grupo aórtico. Ao doppler contínuo foram também calculados o pico de gradiente e o gradiente médio. A área valvar foi calculada a partir do Pressure Half Time ( $\mathrm{A}=\frac{220}{\mathrm{PHT}}$ ).

A determinaçāo de insuficiência valvar foi analisada ao doppler pulsado e ao mapeamento de fluxo a cores.

A análise estatística foi redigida em microcomputador tipo IBM/AI-386, utilizando-se programas de processamento estatístico contidos no software EPI INFO, VER 5.Ø1a, distribuído pela USD, INC., Stone Moutain, GA. USA. A nova "One Way" e o teste do Qui quadrado foram aplicados às comparaçōes efetuadas na análise estratificada dos resul- 
VANDRECIC, M. O.; GONTIJO FILHO, B.; OLIVEIRA, S. A.; PAULA E SILVA, J. A.; FANTINI, F. A.; BARBOSA, J. T.; AVELAR, S. O. S.; PAWLOWSKI, A.; ANDRADE, C. A.; MIOTTO, H. C.; BRAGA, M. A.; GUTIERREZ, C. - Tratamento anticalcificante de bioprótese: resultado clínico inicial; Rev. Bras. Cir. Cardiovasc., 7 (2):112-120, 1992.

TABELA 1

ANÁLISE DO CONTEÚDO DE CÁLCIO APÓS IMPLANTE EM RATOS

\begin{tabular}{|c|c|c|c|c|c|c|}
\hline \multirow[t]{2}{*}{ EXPERIMENTOS } & \multirow{2}{*}{$\begin{array}{c}\text { PERIODO } \\
\text { (Meses) }\end{array}$} & \multicolumn{3}{|c|}{ GRUPO P.S. } & \multicolumn{2}{|c|}{ GRUPO CONTROLE } \\
\hline & & $=x+1$ & $\begin{array}{c}\mu g / m g ~ d e \\
\text { tecido }\end{array}$ & $\begin{array}{l}N^{\circ} \text { de } \\
\text { implantes }\end{array}$ & $\begin{array}{c}\mu g / m g ~ d e \\
\text { tecido }\end{array}$ & $\begin{array}{c}N^{2} \text { de } \\
\text { implantes }\end{array}$ \\
\hline 1 & $\begin{array}{l}1 \\
3,5\end{array}$ & & $\begin{array}{l}7,1(11,1) \\
2,3(1,6)\end{array}$ & $\begin{array}{l}21 \\
16\end{array}$ & $\begin{array}{r}97,7(30,5) \\
245,0(24,4) \\
\end{array}$ & $\begin{array}{l}19 \\
19 \\
\end{array}$ \\
\hline ॥ & 3 & & $3,8(4,1)$ & 14 & $177,8(12,6)$ & 12 \\
\hline
\end{tabular}

tados. Os intervalos de confiança foram definidos por parâmetros da curva normal ou pela distribuiçāo de Student, inclusive para as proporçōes e percentagens. $O$ nível de significância estatística adotado é de $5 \%$.

\section{RESULTADOS}

\section{Experimentação Animal em Ratos}

O resultado dos implantes subcutâneos em ratos (Tabela 1) expressam de modo significativo a menor quantidade de cálcio por miligramo de tecido seco, comparado ao grupo controle, em ambos os ensaios. Para referência, o tecido que nāo foi implantado possui de 0,2 a 0,5 nanogramos de cálcio por miligramo de tecido seco.

\section{Implantes Ortotópicos em Carneiros em Posição Mitral}

O grupo das biopróteses tratadas pelo P.S. teve $100 \%$ de sobrevida em 6 meses. O cateterismo cardíaco foi normal, demonstrando desempenho hemodinâmico adequado sem gradientes significativos. Em contraste, no grupo controle houve 3 óbitos secundários à insuficiência cardíaca, após 1,2 e 4,5 meses. Dois outros carneiros foram sacrificados devido à insuficiência cardíaca refratária aos 3 e 4 meses. Apenas 1 carneiro sobreviveu, aos 6 meses, sem complicaçōes. $O$ aspecto visual do grupo P. S. mostrou os folhetos preservados, diminuiçāo do pannus, isto é, com mínimo processo proliferativo. O grupo controle: excesso de pannus e calcificaçōes grosseiras.

O exame radiológico, segundo técnica convencional (mamografia), demonstrou ausência de calcificação no grupo tratado pelo P.S. e áreas extensas de calcificaçāo no grupo controle. A análise bioquímica das biopróteses implantadas (Gráfico 1) demonstra que o percentual de cálcio encontrado no tecido tratado foi de 80 vezes menor na base dos folhetos e de 40 vezes menor no corpo dos folhetos.
A calcificaçāo foi expressada em nanogramos de cálcio por miligramo de tecido seco por mês.

\section{Resultado dos Testes de Citotoxicidade}

Os resultados obtidos dos testes de citotoxicidade foram:

1) Teste de citotoxicidade para fibroblastos humanos. Não houve alteraçōes morfológicas ou citotóxicas nos fibroblastos no período de 24 horas.

2) Os implantes subcutâneos demonstraram apenas leve resposta irritativa.

3) O contato direto com sangue humano analisado com a espectofotometria nāo demonstrou hemólise.

\section{Resultado do Teste de Fadiga}

Todas as 6 biopróteses tratadas pelo P. S. e testadas pelo duplicador de pulso, segundo normas vigentes sugeridas por Gabby, ao cabo de $50 \mathrm{mi}-$ Ihōes de ciclos, nāo apresentaram qualquer alteração no tecido, na abertura, no fechamento, gradientes ou insuficiência.

\section{GRÁFICO 1}

ANÁLISE QUANTITATIVO DO CÁLCIO EM BIOPRÓTESES TRATADAS PELO P.S. APÓS IMPLANTE DE 6 MESES EM CARNEIROS

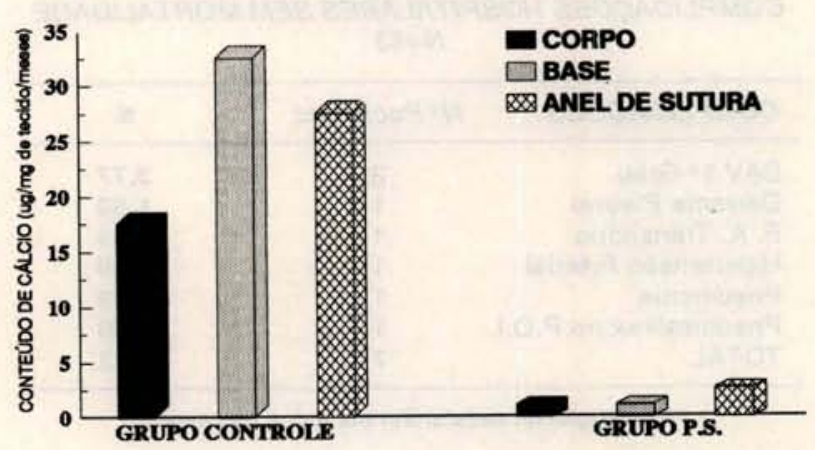


VANDRECIC, M. O.; GONTIJO FILHO, B.; OLIVEIRA, S. A.; PAULA E SILVA, J. A.; FANTINI, F. A.; BARBOSA, J. T.; AVELAR, S. O. S.; PAWLOWSKI, A.; ANDRADE, C. A.; MIOTTO, H. C.; BRAGA, M. A.; GUTIERREZ, C. - Tratamento anticalcificante de bioprótese: resultado clínico inicial; Rev. Bras. Cir. Cardiovasc., 7 (2):112-120, 1992.

TABELA 2

TIPOS DE PROCEDIMENTOS CIRURGICOS - INDICAÇĀO DE CIRURGIAS PRÉVIAS OU TROCAS $N=55$

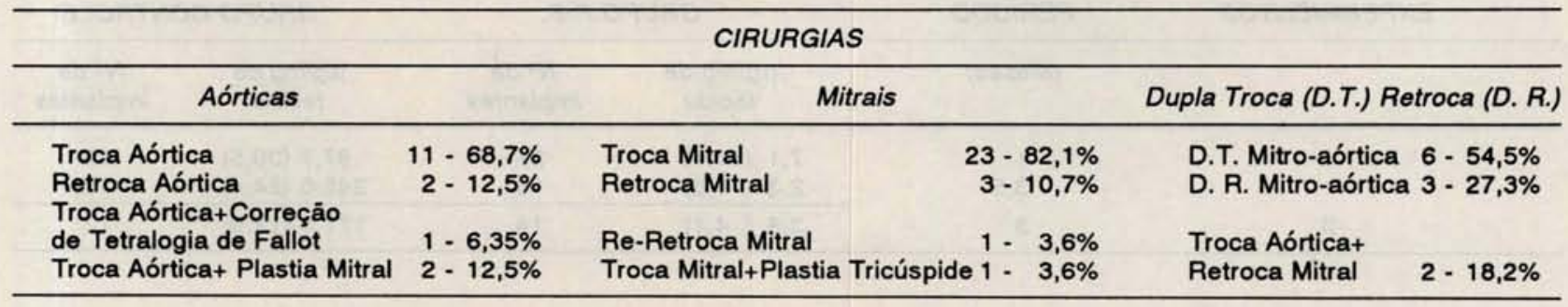

\section{Resultados do Estudo Clínico}

Dos 55 pacientes submetidos a troca de valva, usando-se 66 biopróteses tratadas pelo P. S., houve 2 óbitos imediatos, decorrentes de distúrbio de coagulação após a circulação extracorpórea e, embora submetidos a reoperaçōes imediatamente, o tipo de hemorragia era difuso e não respondia aos meios terapêuticos conhecidos. A mortalidade hospitalar foi de 2 em 55 pacientes $(3,6 \% \pm 4,9 \%)$. Os pacientes submetidos a troca aórtica, troca mitral e dupla troca (Tabela 2) demonstram um número considerável de re e re-retrocas, assim como das duplas trocas em pacientes portadores de endocardite e prévios procedimentos valvares. As complicaçōes não fatais desses 53 pacientes estão relacionadas na Tabela 3 e são comuns a esse tipo de procedimentos, sem ter relação com o uso desta nova prótese. A classe funcional pós-operatória demonstra que 37 pacientes $(65,5 \% \pm 12,1)$ se encontram em classe I e 16 pacientes $(30,9 \% \pm 12,1)$ em classe II. A comparação da classe funcional dos pacientes que mudaram de classe mostra que a totalidade dos sobreviventes passou para as fases I ou II, sendo estatisticamente significativa ( $p<$ 0,001 ) a diferença existente entre o pré e 0 pósoperatório (Gráfico 2). Durante o período de hospitalização e de seguimento à análise laborato-

TABELA 3

COMPLICAÇŌES HOSPITALARES SEM MORTALIDADE $N=53$

\begin{tabular}{lcc}
\hline COMPLICAÇŌES & NoPacientes & $\%$ \\
\hline BAV $1^{\circ}$ Grau & 2 & 3,77 \\
Derrame Pleural & 1 & 1,89 \\
F. A. Transitória & 1 & 1,89 \\
Hipertensāo Arterial & 1 & 1,89 \\
Pneumonia & 1 & 1,89 \\
Pneumotórax no P.O.I. & 1 & 1,89 \\
TOTAL & 7 & 13,22 \\
\hline
\end{tabular}

A evoluçáo foi satisfatória em todos os casos. rial (hematologia e bioquímica do sangue) não demonstrou evidência de hemólise nem toxicidade renal ou hepática. $O$ resultado da análise pela ecodopplercardiografia é apresentado na Tabela 4 e demonstra performance adequada da função miocárdica e da nova bioprótese.

\section{COMENTÁRIOS}

A necessidade do substituto valvular ideal é reconhecida e esperada por todos. Hoje, o nosso armamentarium possui próteses cuja performance é restrita, por um lado, pela necessidade do uso anticoagulantes, que, além de um manuseio difícil, produzem doenças iatrogênicas graves e seqüelas; por outro lado, a durabilidade das biopróteses é muito limitada em crianças e jovens, acarretando alto indice de reoperaçôes 4 .

Vários fatores interferem na escolha do tipo de substituto valvular, tais como: idade, nível sócioeconômico, sexo, tipo de doença valvar e outros ?

No nosso meio, o uso de biopróteses predomina sobre as próteses mecânicas, principalmente

\section{GRÁFICO 2 \\ CLASSE FUNCIONAL COMPARATIVA PRÉ E PÓS-OPERATÓRIA}

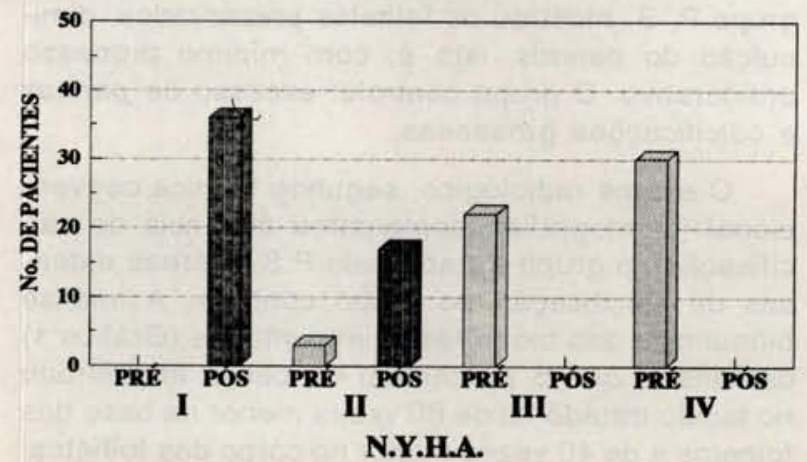


VANDRECIC, M. O.; GONTIJO FILHO, B.; OLIVEIRA, S. A.; PAULA E SILVA, J. A.; FANTINI, F. A.; BARBOSA, J. T.; AVELAR, S. O. S.; PAWLOWSKI, A.; ANDRADE, C. A.; MIOTTO, H. C.; BRAGA, M. A.; GUTIERREZ, C. - Tratamento anticalcificante de bioprótese: resultado clínico inicial; Rev. Bras. Cir. Cardiovasc., 7 (2):112-120, 1992.

TABELA 4

RESULTADOS DA ANÁLISE ATRAVÉS DA ECODOPPLERCARDIOGRAFIA EM 53 PACIENTES PACIENTES AÓRTICOS

\begin{tabular}{llcl}
\hline Parâmetros & \multicolumn{3}{c}{ Diâmetros } \\
& 23 & 25 & 27 \\
\hline V. Max & 2,9 & 2,5 & 2,4 \\
V. Média (M/S) & 1,32 & 1,45 & 1,6 \\
Área Valvar & 2,20 & 2,35 & 2,55 \\
\hline
\end{tabular}

\section{PACIENTES MITRAIS}

\begin{tabular}{lccc}
\hline Parâmetros & \multicolumn{3}{c}{ Diâmetros } \\
& 27 & 29 & 31 \\
\hline V. Max & 1,5 & 1,6 & 1,4 \\
V. Média (M/S) & 1,25 & 1,15 & 1,05 \\
P.H.T. & 88,0 & 77,0 & 70,0 \\
Área Valvar & 2,5 & 3,0 & 3,1 \\
\hline
\end{tabular}

pela restriçāo sócio-econômica, custo, estoque e impossibilidade de um seguimento seguro, na maioria dos pacientes.

É fato conhecido que a falência das próteses mecânicas é geralmente súbita e grave. Já nas biopróteses, essa deterioração é lenta, permitindo, em geral, tratamento clínico ou cirúrgico da complicação.

A possibilidade de um novo tratamento das biopróteses porcinas, usando-se o método P.S. que atua na mineralizaçāo desses tecidos, permitindo uma atenuação através da modificação química a nível celular, retardando a atração do cálcio aos tecidos, vem preencher a nossa necessidade de um substituto valvular cuja durabilidade seja maior.

Os resultados obtidos nos implantes subcutâneos de ratos, no período de três meses, demonstrou, inequivocamente, a sua ação, retardando, de modo efetivo, a calcificação dos tecidos.

Sabendo-se que o tempo de observação deste experimento corresponde ao seguimento de vários anos de uso em humanos, podemos concluir que o tratamento P.S. deve retardar, de modo significativo, o aparecimento da calcificação em biopróteses ortotópicas em pacientes.

O segundo experimento de implante, em posição mitral de carneiros, é mais convincente, já que o modelo é o ideal para esse tipo de experimentaçāo. A prótese está em contato íntimo com o sangue e com os strees mecânico, fatores reconhecidos e determinantes das complicaçōes degenerativas e calcificantes das biopróteses. O grupo P.S. sobreviveu, sem complicaç̋̉es, 6 meses de sequimento. Ao explante, as características histológicas e funcionais dessas biopróteses mostraram-se preservadas. A qualidade das fibras colágenas, tanto na microscopia de luz como na análise da sua ultraestrutura, demonstrou o caráter ondulado dessas fibras, sem fragmentaçāo. A diminuiçāo considerável do pannus demonstra que houve maior aceitaçăo por parte do recipiente, limitando ao mínimo a proliferaçāo excessiva comumente encontrada. A análise da concentração de cálcio no tecido tratado pelo P.S. de 85 vezes menor do que no grupo controle, a leve proliferaçăo perivalvular e o tempo de implante de 6 meses, que corresponde a 20 anos em pacientes, sugere que o tratamento P.S. poderá, de modo significativo, reduzir a calcificação das biopróteses de porcino Biocór, conseqüentemente, prolongando a sua durabilidade. Os testes citotóxicos realizados no Biocór Centro de Pesquisas demonstraram que o tratamento P.S. nāo é tóxico, não produz hemólise e a reação celular em implantes desse tecido em cobaias foi leve. A qualidade das biopróteses, após os testes de fadiga, comprovaram a tolerância adequada dos tecidos a este novo tratamento.

Os resultados clínicos confirmam que este novo tratamento é bem tolerado por pacientes, mesmo em vigência de endocardite. A mortalidade hospitalar está dentro da média internacional para esses procedimentos. As complicaçōes não fatais são comuns a esses tipos de procedimentos. Não houve complicaçōes relacionadas a esta nova prótese.

O seguimento desses pacientes usando exames clínico, ecocardiográfico e de sangue (hematológico e bioquímico), até o presente, demonstrou perfeita tolerância dessa nova prótese, sem efeitos colaterais.

Baseados nos resultados experimentais e clinicos obtidos com o novo tratamento anticalcificante P.S., acreditamos que a durabilidade das biopróteses poderá ser significativamente prolongada, principalmente em crianças e jovens. Esse grupo inicial de pacientes tem por objetivo demonstrar se, ao longo dos anos, essa afirmação se tornará verdadeira. 
VANDRECIC, M. O.; GONTIJO FILHO, B.; OLIVEIRA, S. A.; PAULA E SILVA, J. A.; FANTINI, F. A.; BARBOSA, J. T.; AVELAR, S. O. S.; PAWLOWSKI, A.; ANDRADE, C. A.; MIOTTO, H. C.; BRAGA, M. A.; GUTIERREZ, C. - Tratamento anticalcificante de bioprótese: resultado clínico inicial; Rev. Bras. Cir. Cardiovasc., 7 (2):112-120, 1992.

RBCCV 44205-169

VRANDECIC, M. O.; CONTIJO FILHO, B.; OLIVEIRA, S. A.; PAULA E SILVA, J. A.; FANTINI, F. A.; BARBOSA, J. T.; AVELAR, S. O. S.; PAWLOWSKI, A.; ANDRADE, C. A. O.; MIOTTO, H. C.; BRAGA, M. A.; GUTIERREZ, C. - Anti-calcificant treatmant of porcine bioprosthesis: ;initial clinical trial. Rev. Bras. Cir. Cardiovasc., 7 (2):112-120, 1992

ABSTRACT: Clinical results with the use of porcine bioprosthesis are satisfactory from the standpoint of hemodynamic performance, low incidence of thromboembolysm providing adequate quality of life. Calcification and tissue tear remain the major complications of bioprosthesis, mainly in children and young patients. Several stratergies were proposed to control or even to avoid calcification; up to the present, none of them have proved to decrease calcification or to prolong their durability. This controlled clinical study was undertaken based upon the quality of anticalcificant effect of the P.S. treatment obtained in animal implants with the Biocor porcine bioprosthesis; the negative results of toxicological analysis of the treated tissue and the good performance in fatigue testing of the P.S. treated Biocor bioprosthesis. The rational of the P.S. treatment is to obtain covalent bounds of the anticalcificant agent to the tissue, in more durable form. From February/1991 to March/1992, 66 treated bioprosthesis were implanted in 55 patients; there were 28 males and 27 femeles. The age ranged from 11 to 68 years. There were $72.7 \pm 11.8$ of patients below 30 years of age. Mean age was 26.6. Rheumatic heart disease was the ethiological factor in $70.9 \% \pm 12.0$. Regular sinus rhythm was present in $70.9 \%$. Preoperative functional class was $40.0 \% \pm 12.0$ and $52.7 \% \pm 13.2$ respectively, for class III and IV of the NYHA; 55 patients underwent valve replacement namely aortic in 16 patients $(29.1 \%$ $\pm 12.0)$; mitral, 28 patients $(50.1 \% \pm 13.21)$ and double valve replacement 11 patients $(20.0 \% \pm 10.6)$. The surgical technique was the conventional, using bouble oxygenator, crystaloid cardioplegia and U type sutures. There were no complications related to the new bioprosthesis. Hospital mortality was 2 in 55 patients or $3.6 \%$. The majority of the 53 patients are in class functional I and II. The follow up is being done quaterly by clinical, echodopplercardiographical and laboratorial tests (hematological and biochemistry). During this period of 13 months, there were no complications related to the newly treated bioprosthesis.

DESCRIPTORS: heart valves prostheses, surgery; heart valves, surgery.

AGRADECIMENTO: Agradecemos ao Dr. Dilermando Fazito Rezende, pela colaboraçāo na análise estatística do trabalho, e ao Departamento de Pesquisas e Publicaçāo do Instituto Biocór.

\section{REFERÊNCIAS BIBLIOGRÁFICAS}

1 AROM, K.V. - Choice of mechanical aortic prosthetic valves. In: EMERY, R. W. \& AROM, K. V. (eds.) The aortic valve. Saint Louis, Mosby-Year Book, 1991. p. 193-203.

AROM, K. V. - Choice of mechanical aortic prosthetic valves. In: EMERY, R. W. \& AROM, K. V. (eds.) The aortic valve. Saint Louis, Mosby-Year Book, 1991. p. 211-216.

BURDON, T. A.; MILLER, D. C.; OYER, P. E.; MITCHELL, R. S.; STINSON, E.B.; STARNES, V. A.; SHUMWAY, N. E. - Durability of porcine valves at fifteen years in a representative North American patient population. J. Thorac. Cardiovasc. Surg., 103: 238-252, 1992.

COSGROVE, D. M. - Valve reconstruction versus valve replacement. In: CRAWFORD, F. A. (ed). Cardiac surgery: state of the art reviews. Philadelphia,
Hanley \& Belfus, 1987. Vol. 1, p. 143.

5 FERRANS, V. J.; BOYCE, S. W.; BILLINGHAM, M. E.; JONES, M.; ISHIHARA, T.; ROBERTS, W.C. Calcific deposits in porcine bioprostheses: structure and pathogenesis. Am. J. Cardiol., 46: 721-734, 1980.

6 GABBAY, S. - Mechanical factors influencing the durability of heart valve pericardial bioprostheses. Trans. Am. Soc. Artif. Intern. Organs, 32: 282-287, 1986.

7 GALLO, I.; NISTRAL, F.; BLASQUEZ, R.; ARBE, E.; ARTINĀNO, E. - Incidence of primary valve failure in porcine bioprosthetic heart valves. Ann. Thorac. Surg., 45: 66-70, 1988.

8 GIRARDOT, J. M. - A method for retarding or preventing the calcification of a prosthesis implanted in a mammal. US patent $n^{\circ} 4,976,733$.

9 GOTT, J. P.; CHIH-PAN; DORSEY, L. M. A.; JAY, J. L.; JETT, G. K.; SCHOEN, F. J.; GIRARDOT, J. A; GUYTON, R. A. - Calcification of porcine valves: a successful new method of antimineralization. Ann. Thorac. Surg., 53: 207-216, 1992.

10 SCHOEN, F. H.; HARASAKI, H.; KIM, K. M.; ANDERSON, H. C.; LEVY, R. J. - Biomaterial- 
VANDRECIC, M. O.; GONTIJO FILHO, B.; OLIVEIRA, S. A.; PAULA E SILVA, J. A.; FANTINI, F. A.; BARBOSA, J. T.; AVELAR, S. O. S.; PAWLOWSKI, A.; ANDRADE, C. A.; MIOTTO, H. C.; BRAGA, M. A.; GUTIERREZ, C. - Tratamento anticalcificante de bioprótese: resultado clínico inicial; Rev. Bras. Cir. Cardiovasc., 7 (2):112-120, 1992.

associated calcification: pathology, mechanisms, and strategies for prevention. J. Biomed. Mater. Res. Appl. Biomater., 22: 11-36, 1988.

11 SCHOEN, F. J.; KUJOVICH, J. L.; LEVY. R. J. - St. John Sutton M. bioprosthetic heart valve pathology, clinical pathologic features of valve failure and pathobiology os calcification. Cardiovasc. Clin., 18: 289-317, 1988.

VRANDECIC, M. O.; GONTIJO FILHO, B.; PAULA E SILVA. J. A.; FANTINI, F. A.; BARBOSA, J. T.; SĀO JOSÉ, M. C.; SANTOS PINTO, C. A.; VIEIRA, G. L.; OLIVEIRA, H. G.; RABELO, S.; PEREDO, E. A.; BARBOSA, M.; MIOTTO, H. C.; BRAGA, M. A.; MACIEL, F. J. - Clinical results with the Biocor porcine bioprosthesis. J. Cardiovasc. Surg., 32: $807-813$, 1991.

VRANDECIC, M. O.; GONTIJO FILHO, B.; RABELO, S. - Clinical experience with a new generation of porcine bioprosthesis. In. BODNAR, E. \& YACOUB, M. (eds.) Biologic \& Bioprothesis Valves. London, Yorke Medical Books, 1986. p. 659-665.

\section{Discussão}

\section{DR. HENRIQUE B. FURTADO} Bauru, SP

Cumprimentos pelo brilhante evento e cumprimentos ao Dr. Mário Osvaldo pela sua contribuição neste tópico tão importante, pela sua gentileza em ter nos enviado o trabalho completo e pela brilhante exposição que ele realiza hoje, neste Congresso. Eu gostaria de citar que, infelizmente, provavelmente por problema de sigilo industrial, o trabalho não cita o grupo químico da droga anticalcificante utilizada. Vários agentes anticalcificantes têm sido utilizados e foram feitos estudos experimentais desde a década de 80 que demonstram que os implantes subcutâneos em carneiros ou bezerros são metodologia científica adequada para se estudar a calcificaçāo de tecidos biológicos. O Dr. Alain Carpentier apresentou trabalho, em 1984, onde compara amostras de cúspides porcinas tratadas por diversos agentes anticalcificantes. Mostrou que, dependendo do método utilizado para avaliar a calcificação, o resultado que se obtém da amostra é diferente. Por exemplo, uma amostra que não tinha grande calcificação em análises mais simples, quando analisada microscopicamente com absorção atômica demonstrou resultados diversos. Chamo a atençāo, também, para que o resultado de tratamento anticalcificante varia dependendo do tecido biológico utilizado. Por exemplo, utilizando a poliacrilamida, o pericárdio bovino apresenta melhores resultados em relação ao tecido porcino. Reforçaria, mais uma vez, o brilhantismo do trabalho, porém gostaria de lembrar que, para acompanha- mento clínico de pacientes jovens com biopróteses, - tempo de 6 meses é ainda muito pequeno. Gostaria de lembrar, também, que os tratamentos anticalcificantes até hoje não mostraram resultados clínicos comparáveis com os resultados experimentais e que as biopróteses na circulação humana são lavadas, nāo havendo correspondência dos estudos experimentais com os estudos clínicos. Espero que, nos próximos anos, sejamos brindados pelo Dr. Mário Osvaldo com uma maior experiência, com resultados muito melhores.

\section{DR. FERNANDO A. LUCHESE Porto Alegre, RS}

Desejo somente fazer uma pergunta ao Dr. Mário Osvaldo e cumprimentá-lo pelo brilhante trabalho. A maioria desses trabalhos que utilizam agentes anticalcificantes mantém o glutaraldeído como forma de preservaçāo da válvula. Portanto, nāo seria o momento de pensarmos em outro agente de preservação e se o glutaraldeído não está diretamente envolvido na calcificação? Será que não deveríamos mudar completamente a técnica?

\section{DR. CAMILO ABDULMASSIH NETO São Paulo, SP}

É necessário salientar que são várias as causas que provocam a mineralização. Um ponto importante é que, hoje, sabemos que o glutaraldeído, e os radicais aldeídos em geral, são um dos causadores da calcificação. Portanto, gostaria de perguntar ao Dr. Mário se, no trabalho dele, nas biopróteses recuperadas, ele estudou o endotélio das válvulas, porque, hoje, o que mais se procura é manter o endotélio do hospedeiro sobre a válvula implantada. Existem vários trabalhos mostrando que o endotélio é muito importante para a preservaçâo da estrutura valvar. Obrigado.

\section{DR. VRANDECIC (Encerrando)}

Agradeço a todos os colegas que, ao longo dos anos, vêm prestigiando o nosso trabalho. Ao Dr. Henrique Barsanulfo Furtado, pela revisão da literatura, e reconhecimento da qualidade do material do texto deste trabalho. A diferença fundamental dos resultados experimentais apresentados é o tempo de experimentação. Neste estudo, o tempo de seguimento dos implantes em posiçāo mitral foi de 6 meses, ao contrário de outros trabalhos, que têm a duração de 3 meses. Ficou evidente que este tratamento anticalcificante atua de modo a impedir a deposição progressiva de cálcio nos tecidos da bioprótese, tendo, inicialmente, uma concentração 
VANDRECIC, M. O.; GONTIJO FILHO, B.; OLIVEIRA, S. A.; PAULA E SILVA, J. A.; FANTINI, F. A.; BARBOSA, J. T.; AVELAR, S. O. S.; PAWLOWSKI, A.; ANDRADE, C. A.; MIOTTO, H. C.; BRAGA, M. A.; GUTIERREZ, C. - Tratamento anticalcificante de bioprótese: resultado clínico inicial; Rev. Bras. Cir. Cardiovasc., 7 (2):112-120, 1992.

de $2,3 \mathrm{mg}$ por miligramo de tecido seco, a qual continua com essa taxa independentemente do tempo, tanto em implantes no subcutâneo de ratos ou implantes das biopróteses tratadas em bezerros. Ao contrário, em outros estudos, a deposição do cálcio é tempo dependente. Estudos recentes, que constam no texto e bibliografia, indicam pelo menos um estudo apresentado, demonstrando a qualidade do tecido porcino valvar que permitem tratamentos químicos anticalcificantes com sucesso, demonstrados em implantes valvares recentemente apresentados por Girardot. Embora o tratamento apresentado por nós possua metodologia multiseqüencial, usando em cada estágio ácidos diversos, ficou provado que a valva aórtica porcina tolera bem este tipo de tratamento. Historicamente, tem proporcionado melhor durabilidade, até o presente momento.
O Dr. Fernando Antonio Lucchese refere-se ao tratamento dos tecidos sem o uso do glutaraldeído; posso afirmar, que é um campo extremamente fértil e que está, também, estudado por nós, com resultados excelentes. É fascinante a pergunta do Dr. Camilo Abdulmassih Neto, a endotelialização dos enxertos em geral e, principalmente, das biopróteses. No Biocór Centro de Pesquisa, temos conseguido a endotelialização total das mesmas, todavia, o grau de adêrencia do endotélio não é suficiente para suportar o fluxo sangüíneo. Meus agradecimentos a todos, principalmente à Comissảo Organizadora, pelo privilégio de discutir, neste Congresso, este trabalho importante que é o produto da contribuição de tantos colegas, que, como eu, acreditam na necessidade e importância de prolongar a vida útil das biopróteses. 